\title{
Rascunhos do contemporâneo III
}

Das trocas e encontros ocorridos ao longo do XIV Congresso Internacional da Associação dos Pesquisadores em Crítica Genética (APCG) Rascunhos do Contemporâneo, este dossiê se inscreve como um de seus vestígios. A nova gestão da APCG, como é o hábito, assumia a equipe editorial da revista e propunha os três dossiês da Manuscrítica. Revista de Crítica Genética que viriam no ano seguinte. A chamada, divulgada em janeiro de 2020, emprestava o tema do congresso e convidava aos pesquisadores participantes daquela ocasião e aos interessados em geral a contribuírem com suas reflexões. As contribuições foram distribuídas dentre os três dossiês, sendo este o terceiro da série.

Sua especificidade é o contato entre os campos argentino e brasileiro da crítica de processos e da crítica genética, celebrado já na época do congresso, em Curitiba, em outubro de 2019. Gostaríamos de abrir esta apresentação do dossiê com o aspecto que atravessou nosso trabalho editorial ao longo do ano: a convivência de duas línguas vizinhas e de dois países vizinhos. A primeira tarefa, desenhada no começo do ano, era de traduzir os conteúdos da plataforma da revista, do português para o espanhol, possibilitando o acesso aos pesquisadores que nesta língua se expressam. Tal gesto resultou na presença de três textos escritos em espanhol que foram acolhidos em nosso dossiê, para conviverem com os textos em português.

A proximidade das línguas permitiu nossa intercompreensão e um alargamento da descoberta de termos nas duas línguas. Este foi um primeiro aspecto que marcou este trabalho editorial, quando identificamos na diferença das línguas um convite para nossa maior aproximação e à construção de reflexões
De los intercambios y encuentros que tuvieron lugar durante el XIV Congresso Internacional da Associação dos Pesquisadores em Crítica Genética (APCG) Rascunhos do Contemporâneo surge este dosier, que se inscribe como una de sus huellas. Como sucede habitualmente, la nueva dirección de la APCG conformó el equipo editorial de la revista y propuso los tres dosieres de Manuscrita. Revista de Crítica Genética, que serían publicados el año siguiente. La convocatoria, lanzada en enero de 2020, tomó prestada la temática del congreso e invitó a los investigadores participantes en el evento así como a los interesados en general a contribuir con sus reflexiones. Los artículos recibidos se distribuyeron entre los tres dosieres, siendo el presente el tercero de la serie, cuya especificidad es el contacto entre los campos argentino y brasileño en el campo de la crítica genética, contacto efectivamente ocurrido en el congreso celebrado en Curitiba, en octubre de 2019. Queríamos abrir esta presentación del dosier compartiendo la impronta que atravesó nuestro trabajo editorial a lo largo del año: la convivencia de dos lenguas vecinas y de dos países también vecinos. De este modo, la primera tarea diseñada a principios de año consistió en la traducción de los contenidos de la plataforma de la revista del portugués al español, permitiendo el acceso a nuevos investigadores. Esta acción derivó en la presencia de tres textos escritos en español que componen nuestro dosier junto a los textos en portugués.

A su vez, la proximidad de las lenguas nos permitió una comprensión compartida así como una ampliación de términos específicos en ambos idiomas que fuimos descubriendo paulatinamente. Este fue un primer aspecto que marcó nuestro trabajo editorial, y que comenzó cuando identificamos, en la diferencia de 
comuns, o que pontuou todas as trocas, em chamadas de vídeo, mensagens de texto e e-mails.

Um segundo aspecto diz respeito ao período do isolamento social, que transformou amplamente todas as trocas sociais e reuniões em encontros digitais. Este contexto trouxe uma fluidez às nossas reuniões por videoconferência. Se antes deste período a comunicação por plataformas de videoconferência era quase exclusivamente posta em prática nas relações sociais e projetos desenvolvidos dentre pessoas geograficamente distantes, a expansão desta forma de interação a todas as pessoas nos trouxe mais uma vez a sensação de proximidade e vizinhança, entre os editores, que estão afastados por quilômetros. O terceiro editor a nós se juntou na metade do ano, trazendo consigo sua experiência editorial, sua disposição a se engajar neste processo que já estava em curso e a embarcar nos vários ajustes, inclusive tecnológicos, enfrentados ao longo do processo.

Aproveitamos este espaço para difundir a migração da revista Manuscrítica. Revista de Crítica Genética para o Portal de Revistas da USP (http://www.revistas.usp.br/manuscritica/), processo que implicou um grande empenho da gestão anterior da APCG e da presente gestão, bem como a dedicação da seção de Convênios da FFLCH-USP e o trabalho da equipe editorial da revista. Agradecemos à Agência USP de Gestão da Informação Acadêmica (AGUIA) pela acolhida da revista e por todo o suporte oferecido neste longo processo de migração. Este dossiê é prova de que o trabalho editorial necessita fundamentalmente de um esforço e de uma disposição coletiva, envolvendo tantos nomes e vontades, conjugados no mesmo fim: de promover a pesquisa científica de qualidade e mantê-la em circulação. Neste idiomas, una invitación a una mayor cercanía así como a la construcción de reflexiones comunes, que marcó todos nuestros intercambios en forma de videollamadas, mensajes de texto y correos electrónicos.

Un segundo aspecto se liga al aislamiento social que hemos atravesado $y$ que, en gran medida, ha transformado todos los intercambios y encuentros sociales forzosamente en encuentros digitales. Este contexto aportó fluidez a nuestras reuniones, ya que si antes de este período la comunicación a través de plataformas de videoconferencia se utilizaba casi exclusivamente en las relaciones y proyectos desarrollados entre personas geográficamente distantes, la expansión de esta forma de interacción nos trajo más de una vez, a quienes estábamos separados por kilómetros de distancia, el sentimiento de cercanía y vecindad. En ese contexto, el tercer editor se sumó al proyecto a mediados de año, trayendo consigo su experiencia editorial, su voluntad de involucrarse en este proceso que ya estaba en marcha, y de embarcarse en los desafíos, incluso tecnológicos, que enfrentamos a lo largo del camino.

En este sentido, queremos aprovechar este espacio y oportunidad para difundir la migración de la revista Manuscrita. Revista de Crítica Genética al Portal de Revistas da

USP (http://www.revistas.usp.br/manuscritica/), proceso que implicó un gran compromiso por parte de la gestión anterior y de la actual de la APCG, así como de la sección Convênios da FFLCH-USP y del equipo editorial de la revista. Agradecemos además a la Agência USP de Gestão da Informação Acadêmica (AGUIA) por la recepción de la revista y por todo el apoyo brindado en este largo proceso de migración. El presente dosier es la prueba de que el trabajo editorial necesita fundamentalmente del esfuerzo y la disposición colectiva, que implica voluntades combinadas con un mismo fin: fomentar la 
sentido, agradecemos muito a todas as pessoas que dispuseram de seu tempo, dedicação e conhecimento a tornar este dossiê possível: autores, equipe editorial, pareceristas, revisor, diagramadora, funcionários da AGUIA e a todos os leitores. É essa força coletiva e plural que garante essencialmente a manutenção de nossa revista e a existência deste dossiê.

O percurso de textos deste dossiê 42 começa com o conjunto de textos que têm em comum um espaço: o museu. Em “Como nasce um museu: Lygia Fagundes Telles e os bastidores do desconhecido Museu da Literatura Brasileira”, descobrimos em um mergulho nos arquivos de Lygia Fagundes Telles seu desejo de oferecer ao amplo público um museu da literatura. Ainda entregues ao arquivo, deixamos vir à tona textos inéditos encontrados pela pesquisadora, autora de "O poeta no Museu: textos inéditos de João Cabral de Melo Neto”. Encerra esta seção o artigo "O processo é a obra: alguns apontamentos sobre a série 'Sobras' de Geraldo de Barros”, em que processo e obra coincidem. Corpo em cena, abrimos espaço para o teatro, para as artes performáticas e para o cinema. Esta seção se inicia "Entre riscos e rabiscos: questões de crítica genética na teatralização de A Pedra do Reino por Antunes Filho”. Ainda no teatro, clássico e contemporâneo são aproximados em "Construir o contemporâneo: Bauchau revendo Antígona, de Sófocles”. Detemo-nos nas artes contemporâneas, nos deixando levar pela "Espiral poética e o tempo da criação em Rubiane Maia: notas em processo”. Este conjunto se fecha com os desenhos e montagens de Eisenstein, na contribuição "Crítica genética en perspectiva: dibujos y montajes de ¡Que viva México!, de Sergei Eisenstein”. investigación científica de calidad y promover su circulación. En este sentido, queremos agradecer especialmente a todas las personas que dispusieron de su tiempo, dedicación y conocimiento para que este dosier fuera posible: autores, equipo editorial, evaluadores, revisor, diagramadora, personal de AGUIA y a todos los lectores. Es esta fuerza colectiva y plural la que garantiza fundamentalmente la continuidad de nuestra revista y la existencia del presente dosier.

El recorrido de este número 42 comienza con un conjunto de textos que comparten un espacio en común: el museo. En "Como nasce um museu: Lygia Fagundes Telles e os bastidores do desconhecido Museu da Literatura Brasileira”, nos sumergimos en los archivos de Lygia Fagundes Telles para descubrir su deseo de ofrecer al público un museo de literatura. Continuando con la temática del archivo, podemos ver cómo salen a la luz textos inéditos hallados por la investigadora y autora en "O poeta no Museu: textos inéditos de João Cabral de Melo Neto”. Cierra esta sección el artículo "O processo é a obra: alguns apontamentos sobre a série 'Sobras' de Geraldo de Barros", en la que obra y proceso coinciden.

Con el cuerpo en escena, abrimos un espacio para el teatro, las artes escénicas y el cine. Esta sección comienza con "Entre riscos e rabiscos: questões de crítica genética na teatralização de A Pedra do Reino por Antunes Filho”. También dentro del terreno del teatro, lo clásico y lo contemporáneo son las nociones que se abordan en "Construir o contemporâneo: Bauchau revendo Antígona, de Sófocles”. Y nos sumergimos en el arte contemporáneo dejándonos llevar por "Espiral poética e o tempo da criação em Rubiane Maia: notas em processo". El conjunto cierra con una lectura de los diseños y montajes de Eisenstein en la propuesta "Crítica genética en perspectiva: dibujos y montajes de ¡Que viva México!, de Sergei Eisenstein”. 
A terceira seção é marcada por dois textos nos quais são propostas discussões de cunho mais teórico sobre a crítica de processos, com "Por uma ciência da imagem: Crítica de Processos de criação e psicanálise como pilares teóricos”, e sobre arquivo, o manuscrito e a digitalização, com "El manuscrito como un cuerpo que insiste”.

$\mathrm{Na}$ seguinte seção são exibidos diários, correspondências e manuscritos. Em "Fractais da literatura: o diálogo epistolar entre Hilda Hilst e Caio Fernando Abreu", a autora resgata a correspondência entre os dois escritores, marcada por longas ausências de Hilda e pela assiduidade de Caio, amizade ainda assim tão relevante para ambos os processos de escrita. Das cartas ao diário, conhecemos "O diário póstumo de Hervé Guibert como espaço de escritura, de decantação da gramática autobiografemática e ato final de um projeto autoficcional”. Sob a defesa do diário como um romance, descobrimos com o autor a noção de autobiografema, notadamente oriunda das discussões recentes a partir da noção barthesiana de biografema. Entre a literatura e a filosofia, o texto que se segue empenha-se "Entre reescritura e expansão do texto: da gênese à criação pós-editorial de Proust e os signos, de Gilles Deleuze”. Fecham este conjunto de textos do dossiê duas contribuições sobre poetas: do lado argentino, apresentamos “Materia y (des)tiempos: las formas de lo contemporáneo en la obra de Darío Canton", e do lado brasileiro, "Processo de Criação e Gênese Imaterial da Poesia de Luiz Bacellar”.

$\mathrm{O}$ conjunto final de textos é marcado por encontros. $\mathrm{O}$ primeiro é um encontro-conversa, do qual nasce "Escrever Para Não Esquecer: Entrevista com Scholastique Mukasonga”, cuja conversa percorreu o contato das diferenças da língua e da aproximação das literaturas africanas de expressão francesa e da literatura brasileira. O segundo surge de um contato tradutório, do francês ao português: "A ontologia do
El tercer apartado se adentra en las discusiones teóricas, en torno a la crítica genética en "Por uma ciência da imagem: Crítica de Processos de criação e psicanálise como pilares teóricos”, y sobre archivo, manuscrito y digitalización en "El manuscrito como un cuerpo que insiste".

La sección siguiente aborda diarios, correspondencias y manuscritos. En "Fractais da literatura: o diálogo epistolar entre Hilda Hilst e Caio Fernando Abreu” la autora rescata una correspondencia signada por las prolongadas ausencias de Hilda y la asiduidad de Caio, y logra dar cuenta de una amistad que resulta clave para los procesos de escritura de los dos autores. Las cartas dan paso al diario, con el artículo "O diário póstumo de Hervé Guibert como espaço de escritura, de decantação da gramática autobiografemática e ato final de um projeto autoficcional”, donde a partir de la defensa del diario como novela, recorremos con el autor la noción de autobiografía, ligada a las recientes discusiones en torno a la noción barthesiana de biografema. Entre la literatura y la filosofía, el siguiente texto propone una lectura situada "Entre reescritura e expansão do texto: da gênese à criação pós-editorial de Proust e os signos, de Gilles Deleuze”. Finalmente, este espacio del dosier cierra con dos contribuciones que abordan las obras de dos poetas: "Materia y (des)tiempos: las formas de lo contemporáneo en la obra de Darío Canton”, por el lado argentino, y "Processo de Criação e Gênese Imaterial da Poesia de Luiz Bacellar”, por el brasileño. El conjunto final de textos está compuesto por encuentros. El primero es un diálogo del que nace "Escrever Para Não Esquecer: Entrevista com Scholastique Mukasonga”, una conversación que aborda el contacto entre las diferencias de la lengua y la aproximación de las literaturas africanas en lengua francesa con la literatura brasileña. El segundo se trata 
negativo: na língua, verdadeiramente, só existem diferenças?”.

Cada um dos apartados que compõem o presente dossiê busca, em sua diversidade temática, oferecer uma entrada para ampliar as discussões atuais em torno da crítica genética. Estas discussões vão desde as reflexões teóricas sobre materiais e objetos de estudo próprios da área até a abordagem concreta de processos criativos de diversas disciplinas artísticas. Desejamos a todos que a leitura dos textos aqui reunidos seja tão grata quanto enriquecedora. de una traducción, en este caso del francés al portugués: "A ontologia do negativo: na língua, verdadeiramente, só existem diferenças?”.

Cada uno de los apartados que componen el presente dossier busca, en su diversidad temática, ofrecer una entrada para ampliar las discusiones actuales en torno a la crítica genética; discusiones que van desde las reflexiones teóricas en torno a materiales y objetos de estudio propios del área hasta el abordaje concreto de procesos creativos de diversas disciplinas artísticas. Les deseamos entonces que la lectura de los textos aquí reunidos sea tan grata como enriquecedora.

Cleber A. Cabral

Katerina Blasques Kaspar

Lea Hafter

Editores no dossiê 


\section{Manuscrítica Revista de Crítica Genética}

São Paulo n. $42 \cdot 2020$

\section{Conselho Editorial}

Alícia Duhá Lose (Universidade Federal da Bahia)

Aline Novais de Almeida (Associação de Pesquisadores em Crítica Genética)

Aparecido José Cirillo (Universidade Federal do Espírito Santo)

Aurèle Crasson (Institut des textes et manuscrits modernes)

Cecília Almeida Salles (Pontifícia Universidade Católica de São Paulo)

Carla Cavalcanti e Silva (Universidade Estadual Paulista)

Claudia Amigo Pino (Universidade de São Paulo)

Edson do Prado Pfutzenreuter (Universidade Estadual de Campinas)

Erica Durante (Brown University/EUA)

Graciela Goldchluk (Universidad Nacional de La Plata)

Josette Monzani (Universidade Federal de São Carlos)

Lea Hafter (Universidad Nacional de La Plata)

Mabel Meira Mota (Universidade Federal da Bahia)

Márcia Ivana Lima e Silva (Universidade Federal do Rio Grande do Sul)

Márcia Edlene Mauriz Lima (Universidade Estadual do Piaú)

Marcos Antonio de Moraes (Universidade de São Paulo)

Maria Eunice Moreira (Pontifícia Universidade Católica do Rio Grande do Sul)

Maria da Luz Pinheiro de Cristo (Universidade Federal do Espírito Santo)

Maria Soledad Falabella (Universidad de Chile)

Max Hidalgo Nácher (Universitat de Barcelona)

Miguel Rettenmaier (Universidade de Passo Fundo)

Moema Rodrigues Brandão Mendes (Centro Universitário UniAcademia e Fundação Casa de Rui Barbosa)

Mônica Gama (Universidade Federal de Ouro Preto)

Patricia Kiss Spineli (Pontifícia Universidade Católica de São Paulo)

Paolo D'Iorio (Institut des textes et manuscrits modernes, CNRS. École normale supérieure de Paris)

Philippe Willemart (Universidade de São Paulo)

Rosa Borges (Universidade Federal da Bahia)

Sérgio Romanelli (Universidade Federal de Santa Catarina)

Sílvia Maria Guerra Anastácio (Universidade Federal da Bahia)

Telê Ancona Lopez (Universidade de São Paulo)

Viviane Araújo Alves da Costa Pereira (Universidade Federal do Paraná) 


$$
\text { DIAGRAMAÇÃO }
$$

Sofia Helena Arneiro Lourenço Barbosa

\section{ILUSTRAÇÕES}

Capa: Sofia Helena Arneiro Lourenço Barbosa Imagem da capa: Fotografia de Katerina Kaspar Fonte: Arquivo pessoal

Manuscrítica é uma publicação da Associação de Pesquisadores em Crítica Genética (APCG) e da Pós-Graduação em Letras Estrangeiras e Tradução Universidade de São Paulo com o apoio da CAPES

\section{DIRETORIA APCG}

Presidente - Edson do Prado Pfützenreuter

$$
\text { (Unicamp) }
$$

Vice-presidente - Patricia Kiss Spineli (PUC-SP)

Membro honorário da APCG - Léa Hafter

(Universidad Nacional de la Plata)

Tesoureira - Katerina Blasques Kaspar (USP)

Secretária Geral - Leonardo Mendes (USP)

Secretária de divulgação - Amayi Koyano (USP)

$1^{\mathrm{o}}$ suplente: Aline Novais de Almeida (USP)

$2^{\circ}$ suplente: Thiago Leão Antunes (USP)

$3^{\circ}$ suplente: Wagner Miranda Dias (PUC-SP)
EDITORES DESTE NÚMERO

Cleber A. Cabral (Uninter)

Katerina Blasques Kaspar (USP)

Lea Hafter (Universidade Nacional de La Plata)

EQUIPE EDITORIAL

Aline Novais de Almeida

Amayi Koyano

Edson do Prado Pfützenreuter

Katerina Blasques Kaspar

Léa Hafter

Leonardo Mendes

Patricia Kiss Spineli

Thiago Leão Antunes

Wagner Miranda Dias

E-mail: manuscritica@gmail.com

Novo portal da revista:

www.revistas.usp.br/manuscritica

UNIVERSIDADE DE SÃo PAULO

Programa de Pós-Graduação

em Letras Estrangeiras e Tradução

Coordenadora da Pós-Graduação

Eliane Lousada

Vice-coordenadora

Adriana Zavaglia 